\title{
Unexpected Reactivity of $N$-Acyl-Benzotriazoles with Aromatic Amines in Acidic Medium (ABAA Reaction)
}

\author{
Guillaume Laconde, * Muriel Amblard, and Jean Martinez* \\ IBMM, Univ Montpellier, CNRS, ENSCM, Montpellier, France \\ E-mail: jean.martinez@umontpellier.fr ;Guillaume.laconde@umontpellier.fr \\ Prof. J. Martinez is also actually high-end foreign expert employed by Wuhan Textile University, granted by the State \\ Administration of Foreign, Experts Affairs, Beijing, China
}

\section{Abstract :}

Despite the large number of methods for the synthesis of amides, formation of the amide bond from aromatic amines has always been a challenge for organic chemists due to their weak nucleophile character. We describe here a new efficient method of amide formation from NAcyl-Benzotriazoles and Aromatic Amines (ABAA reaction) including aniline derivatives, in acidic conditions. This reaction is selective for aromatic amines, since aliphatic amines did not react under the same experimental conditions. Using the ABAA reaction, we have synthesized a series of aromatic amide compounds including labelled enzyme substrates, in excellent yield. The ABAA reaction also allowed the one-pot synthesis of Nordiazepam, which is a precursor of the anxiolytic Diazepam (Valium ${ }^{\circledR}$ ). This procedure opens new ways of synthesis of amides from aromatic amines, as well as of heterocyclic structures.

\section{Introduction}

The amide bond is among the most important functional groups, not only in peptides and proteins, but also in natural products,[1] pharmaceutical drugs,[2] agrochemicals, and most of bioactive compounds.[3] Numerous studies have been devoted to the development of efficient methods for the construction of amide linkages, [4-6] most of them resulting from condensation of carboxylic acids with amines. Some other methods involve transamidation,[7] carbamates,[8] S-nitrosothiacids,[9] sulfinyl-amides,[10] oxidative amidation of aldehydes,[11] and amidation of esters.[12] However, despite the efficiency of these methods, the coupling of aromatic amines is still problematic due to their low nucleophile character. Aromatic amines are usually reacted with acyl chlorides,[4-6] and the use of high temperatures and microwaves is often required to obtain an acceptable coupling, which according to the principle of "green chemistry" needs to be improved.[13] The problem is even more tedious when less reactive substituted aromatic amines are used. In this study, we report on the unexpected synthesis of aromatic amides from benzotriazole-activated carboxylic acids (Btcarboxylic acids), and a variety of aromatic amines, in acidic medium. This coupling was shown particularly efficient and attractive. Indeed, it also turned out to be selective for aromatic amines vs. more nucleophile aliphatic amines. This unexpected reactivity was applied to the preparation of several aromatic amides including well-known enzyme substrates, as well as to the synthesis of the benzodiazepine derivative, namely Nordiazepam, which is a precursor of the well-known 
drug Valium ${ }^{\circledR}$ (Diazepam), used for the treatment of anxiety, alcohol withdrawal, muscle spasms, and certain types of seizures.[14] Bt-activated carboxylic acids have been introduced by Katritzky et al.,[15] and have been used for the synthesis of amides.[16] A large panel of reactions have been described in efficient N-, S-, O- and C-nucleophilic substitutions, using versatile $\mathrm{N}$-acyl-benzotriazole derivatives, in which the benzotriazol- 1-yl (Bt) group serves as an halogen substitute.[17] Therefore, Nacyl- benzotriazoles offer numerous advantages over their halogen analogues, including they can be isolated in high yields, in crystalline form, they are usually stable in air (and even in water for short periods at $20^{\circ} \mathrm{C}$ ), and are more reactive than the corresponding $\mathrm{N}$-acyl-imidazoles. We have recently developed a simple and efficient method for the synthesis of activated Bt-carboxylic acids, including Bt-amino acids, from $\mathrm{N}$ protected amino acids and benzotriazole. The reaction was carried out in the presence of $\mathrm{N}$ propanephosphonic acid anhydride (T3P), in a mixture of pyridine/DMF, at room temperature.[18]

\section{Results and Discussion}

We have investigated the reactivity of fluorenylmethyloxy-carbonyl-( L)phenylalanine-Bt [Fmoc-(L)Phe-Bt] 1 towards 2-aminobenzophenone 2, one of the most widely used element for the construction of the benzodiazepine ring.[19] The coupling reaction was performed using a standard procedure, in basic medium, in dichloromethane (DCM) as solvent. It consisted in mixing 1.1 equivalents of Fmoc-(L)Phe-Bt 1, 1 equivalent of 2 -aminobenzophenone 2 at a 0.02 $\mathrm{mol} / \mathrm{L}$ concentration in DCM, in the presence of 10 equivalents diisopropylethylamine (DIEA), at room temperature. After 3 hours, no reaction occurred, while some degradation of the starting material was observed. About $20 \%$ of Fmoc-(L)Phe-Bt 1 was converted into Fmoc-(L)Phe$\mathrm{OH}$. We then decided to study the reactivity of Bt-derivatives in acidic medium that should induce protonation of the Bt heterocyclic structure, further increasing the reactivity of the activated species.

We choose trifluoroacetic acid, extensively used in peptide synthesis for the removal of acid labile protecting groups, including the tert-butyloxycarbonyl (Boc) N-protecting group. The reaction of Fmoc-(L)Phe-Bt 1 with 2-amino benzophenone 2 was then performed in the same experimental conditions than those described above, but replacing DIEA by TFA (10 equiv.). Remarkably, the corresponding amide product 3 resulting from the coupling of compound 1 with the aromatic amine 2 was detectable after only 30 minutes, and the reaction was completed within 3 hours, affording quantitatively the desired amide 3 (Scheme 1).

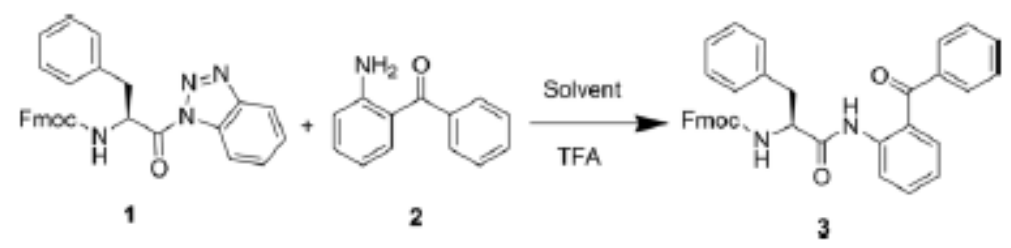

Scheme 1. Synthesis of compound 3. 
To get insight into the mechanism of this reaction, several experimental conditions were tested, and the on-going reaction between Fmoc-(L)Phe-Bt 1 and 2-aminobenzophenone 2 was monitored by HPLC at 214 and $254 \mathrm{~nm}$.

We first have studied the influence of the solvent on the coupling, in the same experimental conditions than previously described. Different solvents were tested among the most commonly used in organic synthesis (Table 1). Toluene showed the best conversion, followed by dichloromethane and acetonitrile. Ethyl acetate, dioxane and THF did not yield any satisfactory amide formation, while DMF gave no conversion at all (Table 1). According to these results, we decided to select toluene as a reference solvent.

Table 1. Synthesis of compound 3. Effect of solvent and TFA amount.

\begin{tabular}{llll}
\hline Entry & Solvent & TFA equiv. & ${\text { Conversion }(\%)^{[a]}}^{[a}$ \\
\hline 1 & DCM & 10 & 65 \\
2 & DMF & 10 & 0 \\
3 & Dioxane & 10 & 12 \\
4 & Toluene & 10 & 72 \\
5 & THF & 10 & 2 \\
6 & Acetonitrile & 10 & 51 \\
7 & AcOEt & 10 & 13 \\
8 & Toluene & 2 & 85 \\
9 & Toluene & 4 & 95 \\
10 & Toluene & 6 & 83 \\
11 & Toluene & 8 & 75 \\
\hline [a] Determined by HPLC after $3 \mathrm{~h}$, and based on 2-aminobenzophenone 2 \\
amount.
\end{tabular}

We then evaluated the role of TFA equivalents on the conversion rate into the final amide 3 , after $3 \mathrm{~h}$ reaction time (Table 1, entries 8-11). The TFA amount did not have a major influence on the formation of amide 3. However, it could be noticed that the kinetics was faster when using 4 TFA equivalents. At a $0.05 \mathrm{M}$ concentration of the Bt derivative, in the presence of 4 TFA equivalents for $18 \mathrm{~h}$, an almost quantitative conversion was obtained. Therefore, we have used these experimental conditions in most of the performed experiments.

After having studied the experimental parameters of this reaction, we extended the scope of the reaction to the preparation of analogues of proline-derived tridentate ligands that are used for the asymmetric synthesis of $\alpha$ - and -amino acids.[20,21] Compound 5 was obtained in a high yield (88\%) by coupling Fmoc-(L)Pro-Bt 4 (1 equiv.) with 2-aminobenzophenone 2 (1.2 equiv.), in the presence of TFA (4 equiv.), in toluene, at room temperature for $18 \mathrm{~h}$ (Scheme 2). The yield of this synthesis was comparable to that obtained by the $\mathrm{MsCl} / \mathrm{N}-\mathrm{Me}-$ Imidazole procedure (yield $87 \%$ ).[22] 


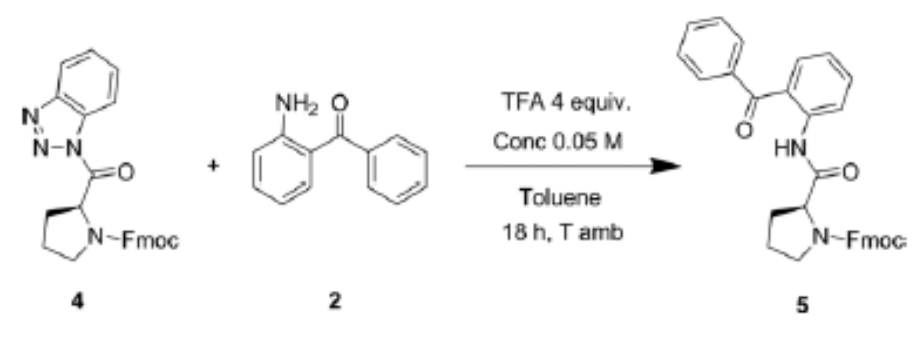

Scheme 2. Synthesis of compound $\mathbf{5}$.

The selectivity of the reaction was investigated by carrying out an experiment using a mixture of two different amines in the same reaction vessel. An aromatic amine, 2-amino-benzophenone 2 (1.2 equiv.), and a primary amine, 4 -methoxybenzylamine 6 (1.2 equiv.), were mixed together and allowed to react with Fmoc-(L)Phe-Bt 1 (1 equiv.), in toluene, at room temperature. Two reactions were initiated in parallel, the first one carried out in acidic medium in the presence of TFA (10 equiv.), and the second one in basic medium in the presence of DIEA (10 equiv.) (Scheme 3).

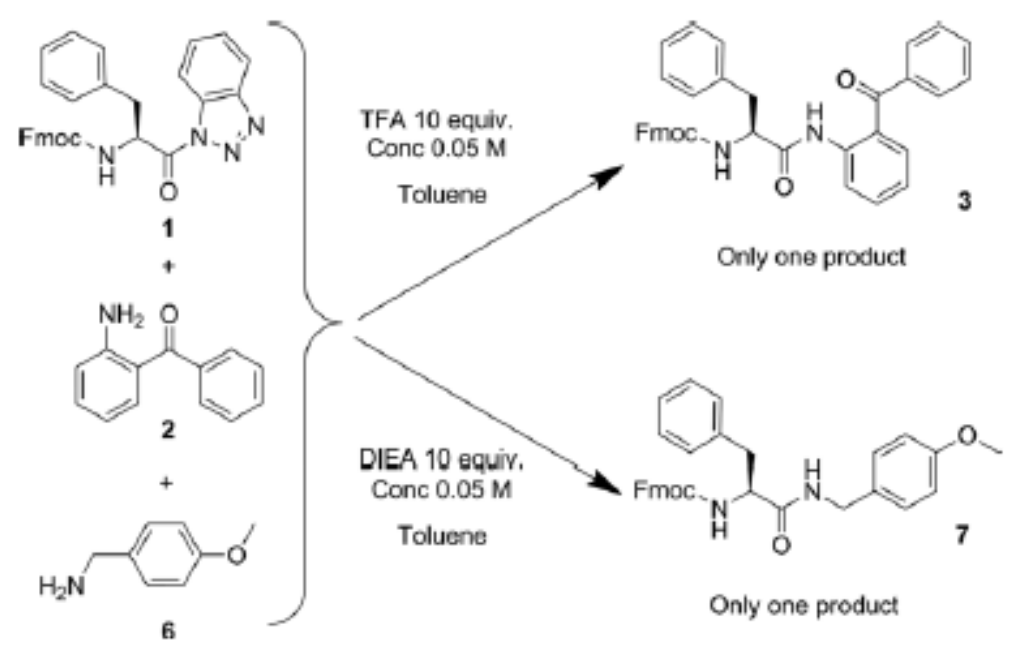

Scheme 3. Amide formation in either acidic or basic medium.

In acidic conditions (TFA), only compound 3 resulting from the reaction of 1 with the aromatic amine 2 was obtained. When basic conditions were used (DIEA), only compound 7 resulting from the coupling of 1 with 6 was observed. The atypical behaviour of Fmoc-(L)Phe-Bt 1 towards the poor nucleophile aromatic amine 2 and the nucleophile primary amine 6 , depending on the acidic and basic experimental conditions, was remarkable. The selective reactivity of aromatic amines vs. aliphatic amines has never been described so far. Not only it greatly simplified the synthesis of amides from aromatic amines, but also it opened the way of several synthetic applications, as a result of the selective reactivity of Bt-activated carboxylic acid with aromatic and aliphatic amines, in either acidic or basic medium. To further explore this reaction we studied the catalytic role of TFA, and we chose a more competitive model. It is well known that para-nitro anilines react poorly with activated carboxylic acids to produce the corresponding amides.[23] We decided to test the coupling of Boc-(L)Phe-Bt 8 with pnitroaniline, in acidic medium (Scheme 4). We selected the Boc protecting group for the amino 
function of phenylalanine to also evaluate its stability in the tested TFA range concentration conditions of the amide bond formation. The reaction was performed with Boc-(L)Phe-Bt 8 (1 equiv.) and 4-nitroaniline (pNA) 9 (1 equiv.), at a $0.05 \mathrm{M}$ concentration, in toluene, varying the TFA amount from 0 to 1 equivalent.

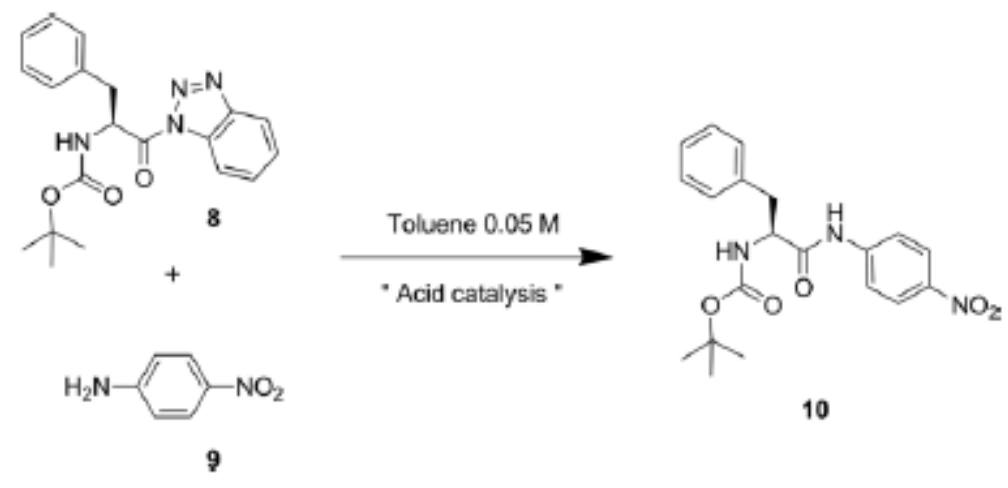

Scheme 4. Synthesis of Boc-(L)Phe-pNA 10.

Almost no reaction took place in the absence of TFA [less than $5 \%$ Boc-(L)Phe-pNa 10 was recovered]. The reaction already proceeded with 0.015625 equivalents of TFA, leading to formation of the expected amide Boc-(L)Phe-pNA 10 in about $25 \%$ yield after $5 \mathrm{~h}$, which supported the role of TFA acting as catalyst. The reaction rate and the yield in compound 10 increased with the increase of TFA amounts. The reaction was completed within 5 hours in the presence of 1 equivalent TFA. This study highlighted the significant role of TFA in the reaction of aromatic amine with Bt-derivatives (Figure 1).

\section{Boc-(L)Phe-pNA}

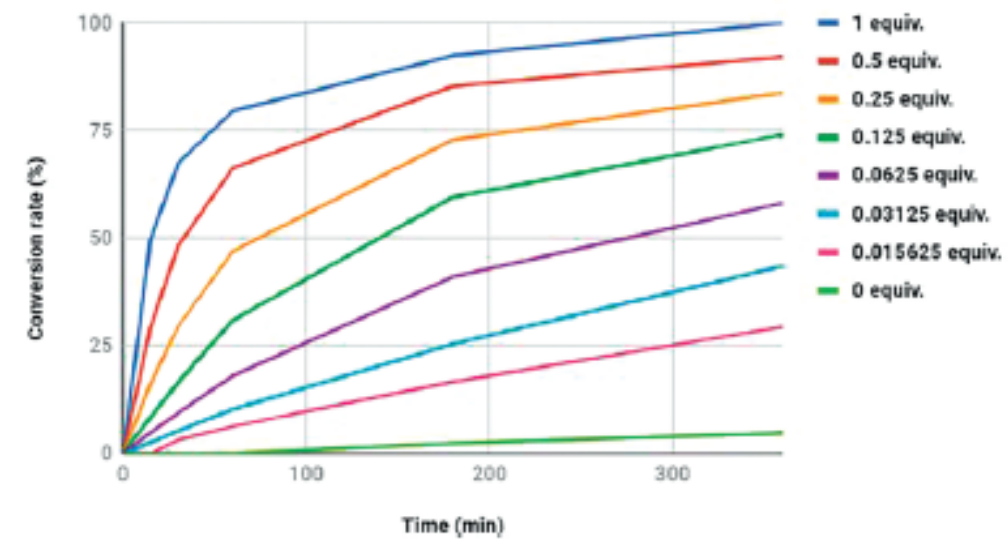

Figure 1. Influence of TFA amounts (serial dilutions) on the synthesis of Boc(L)Phe-pNa 10 [determined by HPLC, and based on Boc-(L)Phe-pNA 10 formation]. 
We then decided to study the nature of the acid on the reaction course, in the same experimental conditions. The formation of Boc-(L)Phe-pNA 10 was evaluated in the presence of 1 equivalent of different types of acids including TFA, $\mathrm{AcOH}, \mathrm{HCOOH}$, benzoic acid, sulfuric acid, and with no acid at all (Figure 2).

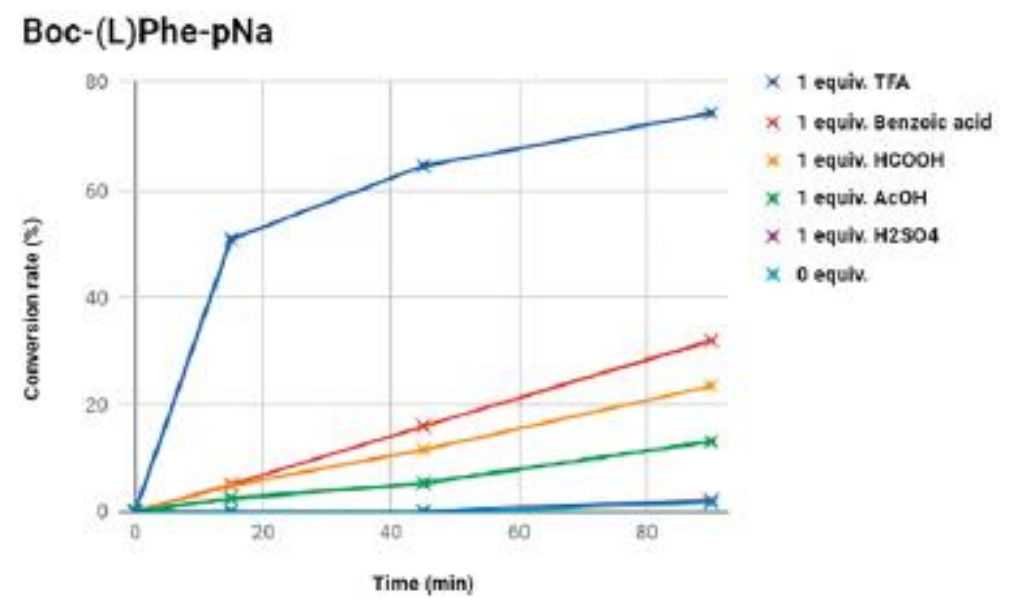

Figure 2. Influence of different acids on the synthesis of Boc-(L)Phe-pNa 10 [determined by HPLC, and based on Boc-(L)Phe-pNA 10 formation].

All carboxylic acids were able to promote the formation of Boc-(L)Phe-pNA 10. While not satisfactory, benzoic acid was more efficient than both formic and acetic acid (about $30 \%$ yield compared to about $15 \%$ yield, after $90 \mathrm{~min}$ ). TFA, which has the strongest pKa among the tested carboxylic acids, induced the highest conversion rate after 90 min reaction (75\% yield). However, in the presence of sulfuric acid, no reaction occurred. These results showed the significance of the carboxylic acid strength (pKa) for achieving a right balance of protonated and non-protonated species that allowed the reaction to proceed.

According to these results, we could hypothesize on a possible mechanism of the reaction.

In the presence of an aromatic amine, the carboxylic acid present in the medium should protonate the benzotriazole $\mathrm{N} 3$ atom, inducing a powerful electron-withdrawing effect. Therefore, this protonated intermediate increased the reactivity of the carbon atom of the carbonyl of the Bt compound, while the two aromatic moieties of both the benzotriazole and of the aromatic amine could interact by pi-stacking, further stabilized by the staple formed with the carboxylate. Thus the amino group of the aromatic amine involved in a pseudocyclic structure should be in a favourable position to react with the carbonyl of the Bt-activated carboxylic acid, yielding to the corresponding amide (Scheme 5). In these experimental conditions, a primary amine will be fully protonated and no reaction will occur. 


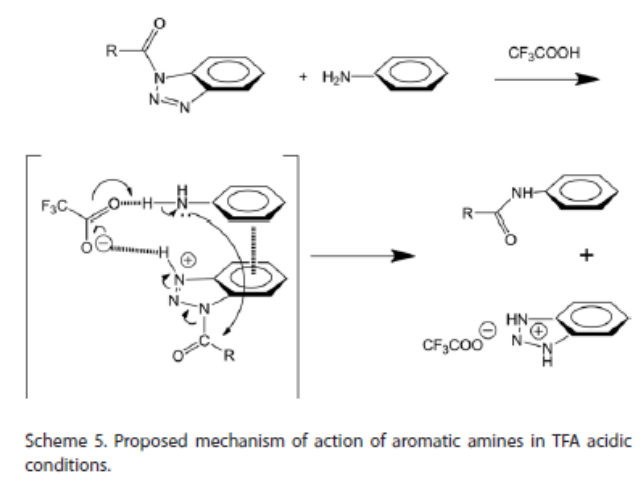

We then decided to exemplify this reaction to other aromatic amines, including a few that are included in compounds of biological interest. We have studied the reactivity of Boc-Gly-Bt 11 with both 7-amino-4-methylcoumarin (AMC) 12, and fluoresceinamine 13, which are used for the synthesis of fluorescent probes (Scheme 6).[24,25] These syntheses are often quite complicate and generally led to the expected compounds in low yields.[26,27]
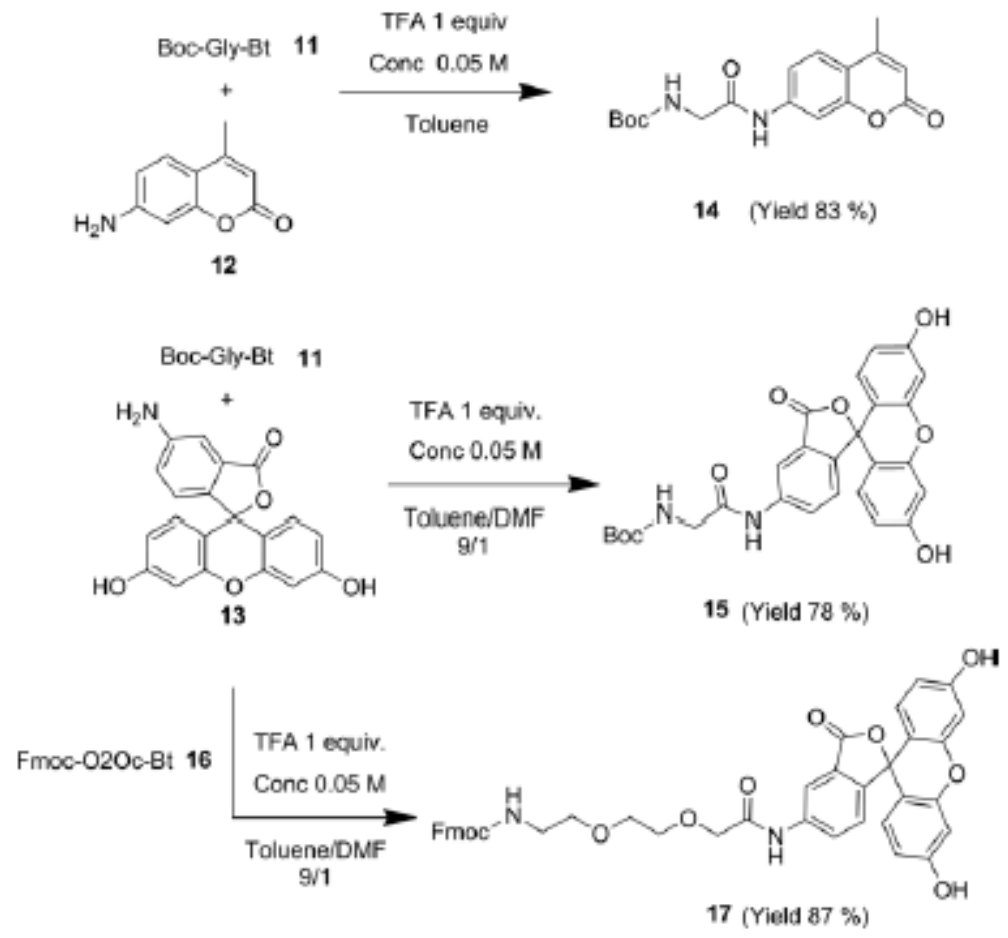

Scheme 6. Reaction of Boc-Gly-Bt 11 with 7-amino-4-methylcoumarin 12, and fluoresceinamine 13, and synthesis of Fmoc-Peg-fluoresceinamide 17.

Starting from Boc-Gly-Bt 11 (1.2 equiv.), reaction with either 7-amino-4-methylcoumarin 12 or fluoresceinamine 13 (1 equiv.), at a concentration of $0.05 \mathrm{M}$ in toluene, in the presence of TFA (1 equiv.) for $18 \mathrm{~h}$ at room temperature, produced compounds 14 and 15 in good yields of $83 \%$ and $78 \%$ respectively, after purification by HPLC (Scheme 6). To allow complete dissolution of fluoresceinamine, $10 \%$ of DMF had to be added to the reaction medium. Alternatively, we also prepared a fluorescein derivative containing a polyethylene (Peg) chain spacer. For that purpose, we have synthesized Fmoc-O2Oc-fluoresceinamide 17 (Scheme 6). 
This compound presented the advantage to keep the fluorescein at a respectable distance from the labelled moiety to avoid interaction with the target, but also to increase the water solubility of the fluorescein-containing compound. The synthesis of this compound 17 is usually quite tedious. To date the only preparation described in the literature resulted in a $22 \%$ yield.[28] Here the synthesis of Fmoc-O2Oc-Bt 16, followed by reaction with fluoresceinamine 13 in the presence of TFA (1 equiv.), in a mixture of toluene/DMF (9:1) at room temperature for $18 \mathrm{~h}$, yielded to the desired compound 17 in $87 \%$ yield after purification by HPLC (Scheme 6).

We then focused on the synthesis of fluorescent enzyme substrates having AMC 12 in their structure. A rapid overview on the various enzyme substrates, most of them being commercially available, showed that quite a number contained an arginine-AMC in their sequence.

We have synthesized Fmoc-(L)Arg(Pbf)-AMC 19, an arginine derivative that will be useful for any synthesis of such substrates. Fmoc-(L)Arg(Pbf)-Bt 18 (1 equiv.) was treated with 7 - amino4-methylcoumarin 12 (1.2 equiv.) in the presence of TFA (1 equiv.), in toluene, for $18 \mathrm{~h}$ at room temperature. The desired compound 19 was obtained after concentration of the solvent and precipitation by addition of diethyl ether (yield $80 \%$ ). In these experimental conditions, the acid labile 2,2,4,6,7-pentamethyldihydro- benzofuran-5-sulfonyl (Pbf) protecting group remained unaffected. The well-known thrombin substrate Z- (L)Pro-(L)Arg-AMC 20[29] was obtained after removal of the Fmoc protecting group from 19 followed by coupling with Z(L)Pro-Bt ( $\mathrm{Z}=$ Benzyloxycarbonyl), and removal of $\mathrm{Pbf}$ in acidic medium (TFA). Compound 20 was recovered in a $56 \%$ yield after purification by HPLC (Scheme 7).

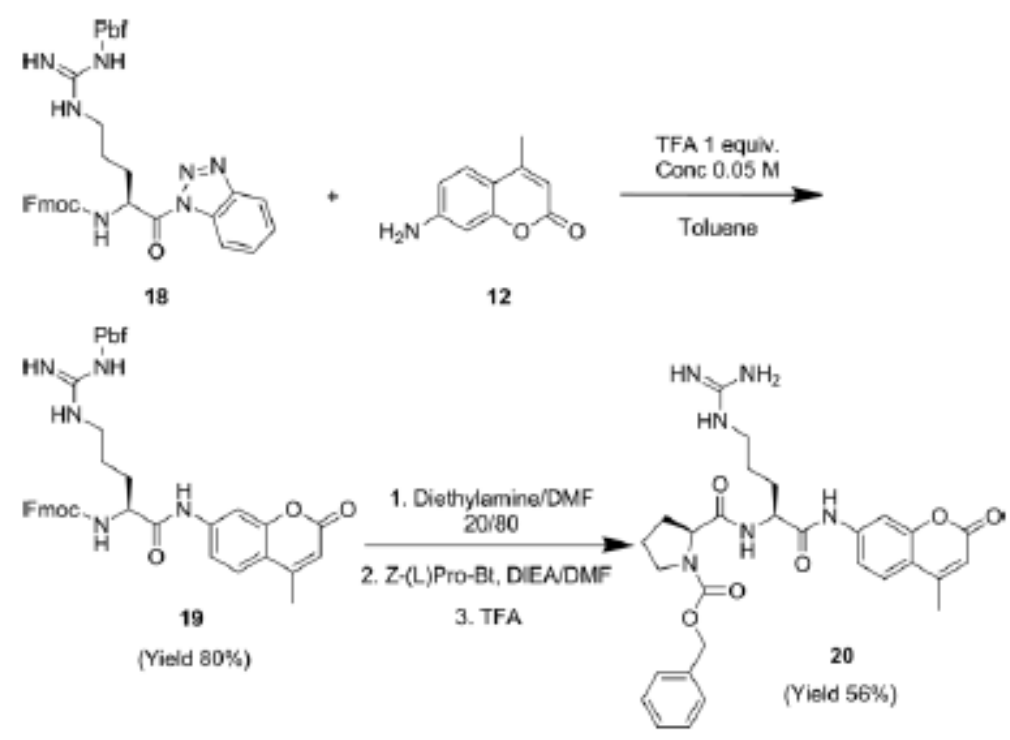

Scheme 7. Synthesis of the fluorescent thrombin substrate Z-(L)Pro-(L)ArgAMC 20.

As a last example, we applied the ABAA reaction to the synthesis of Nordiazepam 22. Its preparation is mainly described in the literature by reaction of chloroacetyl chloride with 2amino-5-chlorobenzophenone 21, followed by cyclization with ammonia.[30] A recent publication has described the one step synthesis of benzodiazepine derivatives from $\mathrm{N}$ - 
carboxyanhydrides (NCA) and 2-aminobenzophenone compounds.[31] Starting from Boc-GlyBt 11 and 2-amino-5-chlorobenzophenone, in the presence of TFA (20 equiv.), in toluene at 60 ${ }^{\circ} \mathrm{C}$ for $6 \mathrm{~h}$, formation of the expected amide was observed. Simultaneous removal of the Boc Nprotecting group followed by cyclisation yielded Nordiazepam 22 in $92 \%$ yield (Scheme 8). This efficient one-pot synthesis of Nordiazepam 22 opened a new straightforward way to the synthesis of new benzodiazepine derivatives known to have high potential in medicinal chemistry.[14]

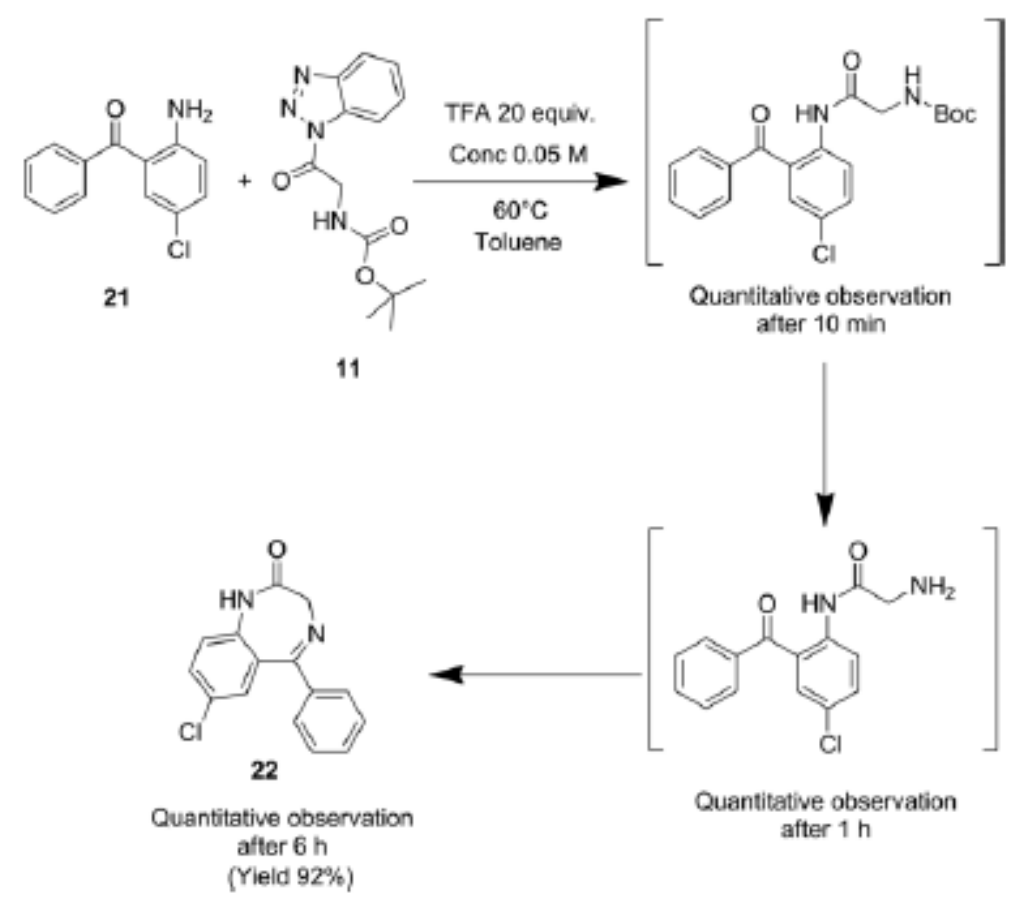

Scheme 8. Synthesis of nordiazepam 22.

\section{Conclusions}

We have proposed a simple, selective and original coupling reaction between Bt-activated carboxylic acids and aromatic amines (ABAA reaction) carried out under acidic conditions, to obtain aromatic amides. This reaction is specific to aromatic amines, which are known to be weak nucleophiles, and that are generally difficult to be coupled with carboxylic acids, vs. aliphatic amines. This new synthetic protocol can be extended to a broad range of reactions, which may have a general interest in organic and medicinal chemistry.

\section{Experimental Section}


All solvents and reagents were used as supplied. Solvents used for LC/MS were of HPLC grade. DMF, DIEA, ACN, TFA were obtained from Sigma-Aldrich. Fmoc amino acid derivatives purchased from Iris Biotech (Marktredwitz, Germany). Samples for LC/MS analyses were prepared in acetonitrile/water (50:50, v/v) mixture, containing 0.1\% TFA. The LC/MS system consisted of a Waters Alliance 2695 HPLC, coupled to a Water Micromass ZQ spectrometer (electrospray ionization mode, ESI+). All the analyses were carried out using a Chromolith Flash $25 \times 4.6 \mathrm{~mm} \mathrm{C} 18$ reversed-phase column. A flow rate of $3 \mathrm{~mL} / \mathrm{min}$ and a gradient of $(0$ $100) \%$ B over 2.5 min were used. Eluent A: water/0.1\% HCO2H, eluent B: acetonitrile/0.1\% $\mathrm{HCO} 2 \mathrm{H}$. UV detection was performed at $214 \mathrm{~nm}$. Electrospray mass spectra were acquired at a solvent flow rate of $200 \mu \mathrm{L} / \mathrm{min}$. Nitrogen was used for both the nebulizing and drying gas. The data were obtained in a scan mode ranging from 100 to $1000 \mathrm{~m} / \mathrm{z}$ or 250 to $1500 \mathrm{~m} / \mathrm{z}$ to in $0.7 \mathrm{sec}$ intervals. 13C and 1H NMR spectra in [D6]DMSO were collected on a Bruker AVANCE $600 \mathrm{MHz}$ spectrometer equipped with a BBFO helium cryoprobe at $298 \mathrm{~K}$. Chemical shifts $(\delta)$ are reported in parts per million using residual nondeuterated solvents as internal references. Spectra were processed and visualized with Topspin 3.2 (Bruker Biospin).

Formation of N-Acyl-benzotriazoles (1, 4, 8, 11, 16 and 18) (general procedure): To a mixture of the carboxylic acid derivative (1 equiv.) and benzotriazole (1.2 equiv.) in DMF ( $1 \mathrm{~mol} / \mathrm{L}$ concentration) was added pyridine (3 equiv.), followed by a solution of T3P $®$ in DMF $(50 \%)$ (1.5 equiv.) added dropwise. The mixture was stirred at room temperature for $1 \mathrm{~h}$. Completion of the reaction was confirmed by HPLC. The mixture was poured into cold water. The precipitated compound was filtered and washed twice with water. After drying for $30 \mathrm{~min}$, the desired product was dissolved in ethyl acetate. The organic layer was dried with anhydrous magnesium sulfate. The solvent was removed under reduced pressure, and the crude was crystallized by addition of hexane.

Fmoc-(L)Phe-Bt (1): Yield $88 \%$. Mp 135-136 ${ }^{\circ} \mathrm{C} .13 \mathrm{C}$ NMR (150.9 MHz, [D6]DMSO): $\delta=$ 170.8, 155.6, 146.1, 143.8, 143.7, 141.3, 135.0, 131.1, 130.9, 129.3, 128.8, 127.7, 127.5, 127.1, 126.6, 125.1, 120.5, 120.0, 114.3, 67.2, 55.7, 47.1, 39.0. LC/MS (ESI+): tR = $1.99 \mathrm{~min}, \mathrm{~m} / \mathrm{z}$ $489[\mathrm{M}+\mathrm{H}]+$. Fmoc-(L)Pro-Bt (4): Yield $92 \%$. Mp 162-163 ${ }^{\circ} \mathrm{C} .13 \mathrm{C}$ NMR $(150.9 \mathrm{MHz}$, [D6]DMSO): $\delta=146.0,144.1,143.9,143.5,141.4,141.3,141.1,140.9,131.3,131.2,130.6$, $130.5,127.7,127.7,127.1,127.1,127.0,126.8,126.6,126.5,126.4,125.2,125.1,124.2,124.1$, 120.2, 120.2, 120.2, 119.7, 119.4, 114.4, 114.5, 67.7, 66.6, 60.0, 59.3, 47.3, 47.1, 47.0, 31.6, 30.7, 24.6, 23.3. LC/MS (ESI+): $\mathrm{tR}=1.81 \mathrm{~min}, \mathrm{~m} / \mathrm{z} 439[\mathrm{M}+\mathrm{H}]+$.

Boc-(L)Phe-Bt (8): Yield $84 \%$. Mp 147-148 ${ }^{\circ} \mathrm{C} .13 \mathrm{C}$ NMR (150.9 MHz, [D6]DMSO): $\delta=$ 171.3, 146.0, 135.3, 131.1, 130.7, 129.3, 129.1, 128.7, 127.3, 126.5, 120.4, 114.4, 55.3, 38.9, 28.2. LC/MS (ESI+): $\mathrm{tR}=1.76 \mathrm{~min}, \mathrm{~m} / \mathrm{z} 367[\mathrm{M}+\mathrm{H}]+$.

Boc-Gly-Bt (11): Yield $94 \%$. Mp 140-140 ${ }^{\circ} \mathrm{C} .1 \mathrm{H}$ NMR (600 MHz, [D6]DMSO): $\delta=8.27$ (d, $\mathrm{J}=8.0 \mathrm{~Hz}, 1 \mathrm{H}), 8.22(\mathrm{~d}, \mathrm{~J}=8.0 \mathrm{~Hz}, 1 \mathrm{H}), 7.79(\mathrm{~m}, 1 \mathrm{H}), 7.62(\mathrm{~m}, 1 \mathrm{H}), 7.53(\mathrm{~m}, 1 \mathrm{H}), 4.80(\mathrm{~d}$, $\mathrm{J}=6.0 \mathrm{~Hz}, 2 \mathrm{H}), 1.42$ (s, $9 \mathrm{H}) .13 \mathrm{C}$ NMR (150.9 MHz, [D6]DMSO): $\delta=169.3,156.0,145.2$, $130.9,130.5,126.6,120.1,113.7,78.6,43.7,28.1 \mathrm{LC} / \mathrm{MS}$ (ESI+): $\mathrm{tR}=1.40 \mathrm{~min}, \mathrm{~m} / \mathrm{z} 277$ [M $+\mathrm{H}]+$. 
Fmoc-O2Oc-Bt (16): Yield $92 \% . \mathrm{Mp} 110-112{ }^{\circ} \mathrm{C} . \mathrm{LC} / \mathrm{MS}$ (ESI+): $\mathrm{tR}=1.71 \mathrm{~min}, \mathrm{~m} / \mathrm{z} 487$ [M $+\mathrm{H}]+$.

Fmoc-(L)Arg(Pbf)-Bt (18): Yield $92 \% . \mathrm{Mp} \mathrm{110-112}{ }^{\circ} \mathrm{C} . \mathrm{LC} / \mathrm{MS}(\mathrm{ESI}+): \mathrm{tR}=1.98 \mathrm{~min}, \mathrm{~m} / \mathrm{z}$ $750[\mathrm{M}+\mathrm{H}]+$.

(S)-(9H-Fluoren-9-yl)methyl2-[(2-benzoylphenyl)carbamoyl]- pyrrolidine 1-carboxylate (5): Yield $87 \%$. Mp 51-52 ${ }^{\circ} \mathrm{C}$. 1H NMR (600 MHz, [D6]DMSO): $\delta=10.58$ (s, $\left.1 \mathrm{H}\right), 10.46$ (s, 1 H), $7.88(\mathrm{~m}, 2 \mathrm{H}), 7.82(\mathrm{~m}, 2 \mathrm{H}), 7.76(\mathrm{~m}, 2 \mathrm{H}), 7.66(\mathrm{~m}, 2 \mathrm{H}), 7.58(\mathrm{~m}, 10 \mathrm{H}), 7.43(\mathrm{~m}, 9 \mathrm{H})$, $7.29(\mathrm{~m}, 6 \mathrm{H}), 7.12(\mathrm{~m}, 1 \mathrm{H}), 7.02(\mathrm{~m}, 1 \mathrm{H}), 4.36(\mathrm{~m}, 1 \mathrm{H}), 4.21(\mathrm{~m}, 4 \mathrm{H}), 4.09$ (m, $3 \mathrm{H}), 3.45$ $(\mathrm{m}, 2 \mathrm{H}), 3.34(\mathrm{~m}, 2 \mathrm{H}), 2.06(\mathrm{~m}, 1 \mathrm{H}), 1.91(\mathrm{~m}, 1 \mathrm{H}), 1.72(\mathrm{~m}, 2 \mathrm{H}), 1.61(\mathrm{~m}, 2 \mathrm{H}), 1.48(\mathrm{~m}, 1$ H), 1.36 (m, 1 H). 13C NMR (150.9 MHz, [D6]DMSO): $\delta=195.7,195.6,170.7,170.4,154.2$, $153.9,143.9,143.6,143.5,140.7,140.5,140.5,137.2,136.6,132.6,132.3,130.8,129.4,129.4$, 129.2, 129.0, 128.2, 127.6, 127.1, 127.0, 126.9, 125.1, 124.1, 123.1, 122.8, 120.0, 67.1, 66.7, $60.5,60.1,47.1,46.6,46.5,46.4,30.4,29.0,23.8,22.8 . \mathrm{LC} / \mathrm{MS}$ (ESI+): tR = $1.94 \mathrm{~min}, \mathrm{~m} / \mathrm{z} 517$ $[\mathrm{M}+\mathrm{H}]+$.

Formation of the amide bond from N-Acyl- benzotriazole derivatives and aromatic amine derivatives (general procedure): To a mixture of the $\mathrm{N}$-Acyl-benzotriazole derivative (1 equiv.) and the aromatic amine derivative ( 1 equiv. $)$ in toluene $(0.05 \mathrm{~mol} / \mathrm{L}$ concentration $)$ was added trifluoroacetic acid (1 equiv.). The mixture was stirred at room temperature. The complete conversion of the final product was determined by HPLC. The solvent mixture was removed under reduced pressure. The crude was purified by preparative HPLC.

Boc-Gly-AMC (14): Yield $83 \%$. Mp 219-222 ${ }^{\circ} \mathrm{C} .1 \mathrm{H} \mathrm{NMR}(600 \mathrm{MHz}$, [D6]DMSO): $\delta=10.39$ $(\mathrm{s}, 1 \mathrm{H}), 7.73(\mathrm{~m}, 2 \mathrm{H}), 7.47(\mathrm{~m}, 1 \mathrm{H}), 7.11(\mathrm{~m}, 1 \mathrm{H}), 6.26(\mathrm{~d}, \mathrm{~J}=1.16 \mathrm{~Hz}, 1 \mathrm{H}), 3.77(\mathrm{~d}, \mathrm{~J}=$ $6.12 \mathrm{~Hz}, 2 \mathrm{H}), 2.39$ (d, J =1.16 Hz, $3 \mathrm{H}), 1.39$ (s, $9 \mathrm{H}) .13 \mathrm{C} \mathrm{NMR}(150.9 \mathrm{MHz}$, [D6]DMSO): $\delta$ $=169.0,160.0,155.9,153.6,153.1,142.2,128.8,128.2,126.0,125.3,115.0,114.9,112.2$, 105.5, 78.1, 43.9, 28.1, 17.9. LC/MS (ESI+): $\mathrm{tR}=1.20 \mathrm{~min}, \mathrm{~m} / \mathrm{z} 333[\mathrm{M}+\mathrm{H}]+$.

Boc-Gly-fluoresceinamide (15): Yield $78 \%$. Mp 215-217 ${ }^{\circ} \mathrm{C} .1 \mathrm{H}$ NMR $(600 \mathrm{MHz}$, [D6]DMSO): $\delta=10.41(\mathrm{~s}, 1 \mathrm{H}), 8.30(\mathrm{~d}, \mathrm{~J}=2.0 \mathrm{~Hz}, 1 \mathrm{H}), 7.82(\mathrm{dd}, \mathrm{J}=9.0,2.0 \mathrm{~Hz}, 1 \mathrm{H}), 7.21$ $(\mathrm{d}, \mathrm{J}=9.0,1 \mathrm{H}), 7.16(\mathrm{~m}, 1 \mathrm{H}), 6.66(\mathrm{~d}, \mathrm{~J}=2.19 \mathrm{~Hz}, 2 \mathrm{H}), 6.58(\mathrm{~d}, \mathrm{~J}=8.93 \mathrm{~Hz}, 2 \mathrm{H}), 6.53$ (dd, $\mathrm{J}=8.93,2.19 \mathrm{~Hz}, 2 \mathrm{H}), 1.40$ (s, $9 \mathrm{H})$. 13C NMR (150.9 MHz, [D6]DMSO): $\delta=169.4,169.0$, 159.9, 156.4, 152.3, 141.0, 129.5, 127.4, 126.7, 124.9, 113.8, 113.0, 110.1, 102.6, 78.6, 44.3, 28.6. LC/MS (ESI+): $\mathrm{tR}=1.27 \mathrm{~min}, \mathrm{~m} / \mathrm{z} 505[\mathrm{M}+\mathrm{H}]+$.

Fmoc-O2Oc-fluoresceinamide (17): Yield $87 \%$. Mp 92-94 ${ }^{\circ} \mathrm{C}$. 1H NMR $(600 \mathrm{MHz}$, [D6]DMSO): $\delta=10.16(\mathrm{~s}, 1 \mathrm{H}), 8.38(\mathrm{~d}, \mathrm{~J}=1.93 \mathrm{~Hz}, 1 \mathrm{H}), 7.93(\mathrm{dd}, \mathrm{J}=8.31,1.93 \mathrm{~Hz}, 1 \mathrm{H})$, $7.87(\mathrm{~d}, \mathrm{~J}=7.44 \mathrm{~Hz}, 2 \mathrm{H}), 7.67(\mathrm{~d}, \mathrm{~J}=7.44 \mathrm{~Hz}, 2 \mathrm{H}), 7.39$ (m, $2 \mathrm{H}), 7.35$ (m, $1 \mathrm{H}), 7.31$ (m, 2 H), $7.20(\mathrm{~d}, \mathrm{~J}=8.31 \mathrm{~Hz}, 1 \mathrm{H}), 6.67(\mathrm{~d}, \mathrm{~J}=2.33 \mathrm{~Hz}, 2 \mathrm{H}), 6.58(\mathrm{~d}, \mathrm{~J}=8.60 \mathrm{~Hz}, 2 \mathrm{H}), 6.54(\mathrm{dd}$, $\mathrm{J}=8.60,2.33 \mathrm{~Hz}, 2 \mathrm{H}), 4.28(\mathrm{~d}, \mathrm{~J}=7.14 \mathrm{~Hz}, 2 \mathrm{H}), 4.20(\mathrm{~m}, 2 \mathrm{H}), 3.70(\mathrm{~m}, 2 \mathrm{H}), 3.62(\mathrm{~m}, 2 \mathrm{H})$, 3.46 (m, $2 \mathrm{H}), 3.17$ (m, $2 \mathrm{H}) .13 \mathrm{C}$ NMR (150.9 MHz, [D6]DMSO): $\delta=169.0,168.5,159.5$, 156.2, 151.9, 147.0, 143.8, 140.7, 139.9, 129.0, 127.5, 127.0, 126.8, 125.1, 124.3, 120.1, 114.1, 
112.5, 109.6, 102.2, 70.3, 70.2, 69.3, 69.1, 65.3, 46.7. LC/MS (ESI+): tR $=1.55 \mathrm{~min}, \mathrm{~m} / \mathrm{z} 715$ $[\mathrm{M}+\mathrm{H}]+$.

Z-(L)Pro-(L)Arg-AMC (20): To a mixture of Fmoc-(L)Arg(Pbf)-Bt 18 (1 equiv.) and 7-Amino4-methylcoumarin 12 (1 equiv.) in toluene $(0.05 \mathrm{~mol} / \mathrm{L}$ concentration) was added trifluoroacetic acid (1 equiv.). The mixture was stirred at room temperature. The complete conversion was determined by HPLC. The solvent mixture was removed under reduced pressure. The residue was purified by preparative HPLC. Fmoc-(L)Arg(Pbf)-AMC 18 (1 equiv.) was solubilized in a mixture of diethylamine/DMF (20:80) and the solution was stirred at room temperature for $3 \mathrm{~h}$. The complete removal of the Fmoc group was determined by HPLC. The solvent mixture was removed under reduced pressure. The residue was dissolved in DMF, and Z-(L)Pro- Bt (1 equiv.) and DIEA (3 equiv.) were added. The mixture was stirred at room temperature for 18 $\mathrm{h}$. The solvent mixture was removed under reduced pressure. The residue was purified by preparative HPLC. Z-(L)Pro-(L)Arg(Pbf)-AMC was recovered and dissolved in trifluoroacetic acid and the mixture was stirred at room temperature for $6 \mathrm{~h}$. The solvent was removed under reduced pressure and the residue precipitated by addition of Et2O. After filtration, the final product Z-(L)Pro-(L)Arg-AMC 20 was obtained as a powder. Yield $56 \%$. Mp 81-82 ${ }^{\circ} \mathrm{C}$. LC/MS (ESI+): $\mathrm{tR}=1.12 \mathrm{~min}, \mathrm{~m} / \mathrm{z} 563[\mathrm{M}+\mathrm{H}]+$.

Synthesis of Nordiazepam (22): To a mixture of Boc-Gly-Bt 11 (1 equiv.) and 2-Amino -5chlorobenzophenone 21 ( 1 equiv. $)$ in toluene $(0.05 \mathrm{~mol} / \mathrm{L}$ concentration $)$ was added trifluoroacetic acid (20 equiv.). The mixture was stirred at $60{ }^{\circ} \mathrm{C}$ for $6 \mathrm{~h}$. The complete conversion was determined by HPLC. The solvent mixture was removed under reduced pressure. Et $2 \mathrm{O}$ was added, and compound 22 precipitated. It was filtered and obtained as a powder. Mp 213- $216^{\circ} \mathrm{C} .1 \mathrm{H} \mathrm{NMR}(600 \mathrm{MHz}$, [D6]DMSO): $\delta=10.73$ (s,1 H), 7.67 (dd, J = 9.0, $2.5 \mathrm{~Hz}, 1 \mathrm{H}), 7.54(\mathrm{~m}, 1 \mathrm{H}), 7.48(\mathrm{~m}, 4 \mathrm{H}), 7.28(\mathrm{~d}, \mathrm{~J}=9.0,1 \mathrm{H}), 7.21(\mathrm{~d}, \mathrm{~J}=2.5,1 \mathrm{H}) .13 \mathrm{C}$ NMR (150.9 MHz, [D6]DMSO): $\delta=169.9,169.0,138.8,138.0,131.9,130.8,130.0,129.4$, $128.4,127.2,126.5,123.2,56.5$. LC/MS (ESI+): tR = $1.17 \mathrm{~min}, \mathrm{~m} / \mathrm{z} 271[\mathrm{M}+\mathrm{H}]+$.

\section{Acknowledgments}

We thank the CNRS, ANR-10-LABX-05-01, and the Universite de Montpellier for financial support. We also thank SIMS platform, LMP (Laboratoire de Mesures Physiques) for providing access to NMR spectroscopy.

\section{Keywords:}

Acylation $\cdot$ Amides $\cdot$ Aniline derivatives $\cdot$ Benzotriazoles $\cdot$ Enzyme substrates

\section{References:}

[1] Y. Chen, E. Wendt-Pienkowski, J. Ju, S. Lin, S. R. Rajski, B. Shen, J. Biol. Chem. 2010, $285,38853-38860$. 
[2] J. S. Carey, D. Laffan, C. Thomson, M. T. Williams, Org. Biomol. Chem. 2006, 4, 23372347.

[3] J. M. Humphrey, A. R. Chamberlin, Chem. Rev. 1997, 97, 2243-2266.

[4] C. A. G. N. Montalbetti, V. Falque, Tetrahedron 2005, 61, 10827-10852.

[5] V. R. Pattabiraman, J. W. Bode, Nature 2011, 480, 471-479.

[6] A. El-Faham, F. Albericio, Chem. Rev. 2011, 111, 6557-6602.

[7] R. M. Lanigan, T. D. Sheppard, Eur. J. Org. Chem. 2013, 2013, 7453-7465.

[8] F. Tinnis, H. Lundberg, H. Adolfsson, Adv. Synth. Catal. 2012, 354, 25312536.

[9] J. Pan, N. O. Devarie-Baez, M. Xian, Org. Lett. 2011, 13, 1092-1094.

[10] J. Bai, B. K. Zambroń, P. Vogel, Org. Lett. 2014, 16, 604-607.

[11] K. Ekoue-Kovi, C. Wolf, Chem. Eur. J. 2008, 14, 9463-9463.

[12] H. Morimoto, R. Fujiwara, Y. Shimizu, K. Morisaki, T. Ohshima, Org. Lett. 2014, 16, 2018-2021.

[13] A. Ojeda-Porras, A. Hernández-Santana, D. Gamba-Sánchez, Green Chem. 2015, 17, 3157-3163.

[14] J. Spencer, R. P. Rathnam, B. Z. Chowdhry, Future Med. Chem. 2010, 2, 1441-1449.

[15] A. R. Katritzky, X. Lan, J. Z. Yang, O. V. Denisko, Chem. Rev. 1998, 98, 409- 548.

[16] A. R. Katritzky, H. Y. He, K. Suzuki, J. Org. Chem. 2000, 65, 8210-8213.

[17] A. R. Katritzky, K. Suzuki, Z. Wang, Synlett 2005, 1656-1665.

[18] G. Laconde, M. Amblard, J. Martinez, Tetrahedron Lett. 2018, submitted for publication; G. Laconde, 2015, FR20140054342 FR3016880 (A1).

[19] D. R. Reddy, F. Ballante, N. J. Zhou, G. R. Marshall, Eur. J. Med. Chem. 2017, 127, 531553.

[20] R. M. Williams, M. N. Im, J. Am. Chem. Soc. 1991, 113, 9276-9286.

[21] T. T. Romoff, A. B. Palmer, N. Mansour, C. J. Creighton, T. Miwa, Y. Ejima, H. Moriwaki, V. A. Soloshonok, Org. Process Res. Dev. 2017, 21, 732-739.

[22] B. Li, J. Zhang, Y. Xu, X. Yang, L. Li, Tetrahedron Lett. 2017, 58, 2374-2377.

[23] S. Kar, M. G. B. Drew, A. Pramanik, J. Mater. Sci. 2012, 47, 1825-1835.

[24] H. Chi, Y. Takemoto, T. K. Nsiama, T. Kato, N. Nishino, A. Ito, M. Yoshida, Bioorg. Med. Chem. 2014, 22, 1268-1275.

[25] Z. Bai, Y. Liu, P. Zhang, J. Guo, Y. Ma, X. Yun, X. Zhao, R. Zhong, F. Zhang, Luminescence 2016, 31, 688-693. 
[26] J. Liang, G. Fang, X. Huang, Z. Mei, J. Li, C. Tian, L. Liu, Sci. China Chem. 2013, 56, 1301-1306.

[27] N. Li, R. K. V. Lim, S. Edwardraja, Q. Lin, J. Am. Chem. Soc. 2011, 133, 15316-15319.

[28] Y. Kimura, T. Komatsu, K. Yanagi, K. Hanaoka, T. Ueno, T. Terai, H. Kojima, T. Okabe, T. Nagano, Y. Urano, Angew. Chem. Int. Ed. 2017, 56, 153-157; Angew. Chem. 2017, 129, $159-163$.

[29] T. Morita, H. Kato, S. Iwanaga, K. Takada, T. Kimura, J. Biochem. (Tokyo) 1977, 82, 1495-1498.

[30] P. Cheng, Q. Zhang, Y. B. Ma, Z. Y. Jiang, X. M. Zhang, F. X. Zhang, J.-J.Chen, Bioorg. Med. Chem. Lett. 2008, 18, 3787-3789.

[31] P. S. Fier, A. M. Whittaker, Org. Lett. 2017, 19, 1454-1457. 